\title{
Experimental determination and modelling of high-pressure phase behavior for the binary system $\mathrm{CO}_{2}+$ cyclooctane
}

Stéphane VITU ${ }^{\mathrm{a}, \mathrm{b}}$, Andrés PIÑA-MARTINEZ ${ }^{\mathrm{c}}$, Romain PRIVAT ${ }^{\mathrm{c}}$, Marie DEBACQ $^{\mathrm{a}, \mathrm{b}}$, Jean-Louis HAVET $^{\mathrm{a}, \mathrm{b}}$, Jean-Luc DARIDON ${ }^{\mathrm{d}}$, Jean-Noël JAUBERT ${ }^{\mathrm{c}, *}$

${ }^{a}$ Université Paris-Saclay, INRAE, AgroParisTech, UMR SayFood, 91300 Massy, France.

${ }^{b}$ CNAM, 2 rue Conté, 75003 Paris, France.

${ }^{c}$ Université de Lorraine, Ecole Nationale Supérieure des Industries Chimiques, Laboratoire Réactions et Génie des Procédés, 1 rue Grandville, 54000 Nancy, France.

${ }^{d}$ Université de Pau et des Pays de l'Adour, Laboratoire des Fluides Complexes et leurs Réservoirs, 64000 Pau, France.

* Corresponding author.

E-mail: Jean-Noel.Jaubert@univ-lorraine.fr

\section{Graphical Abstract:}

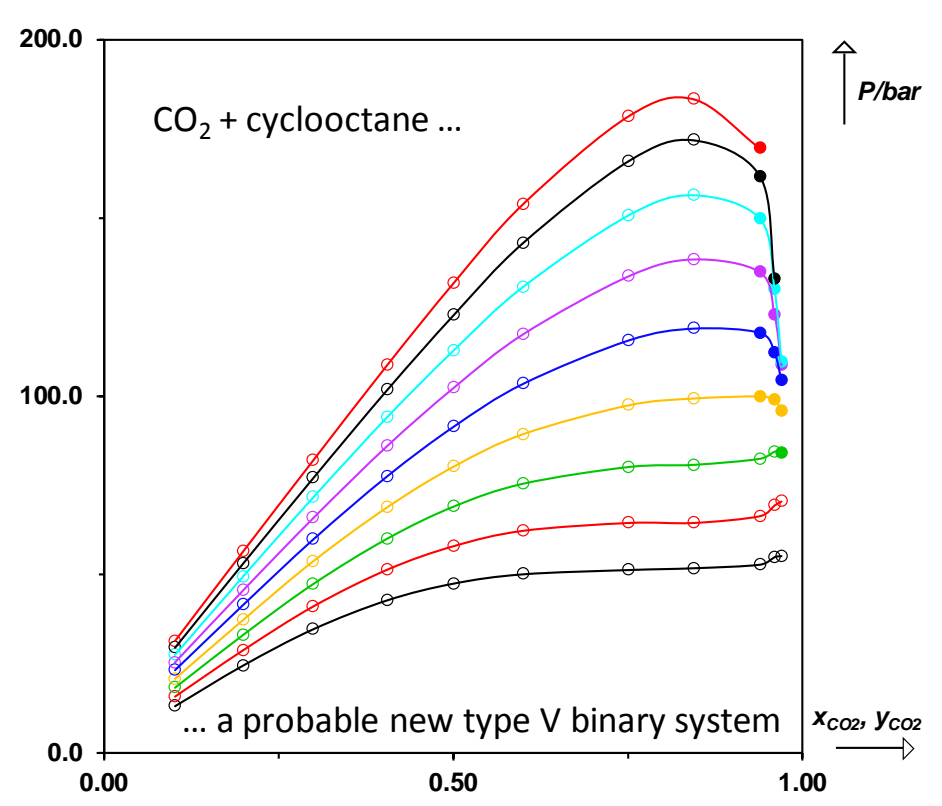

Experimental determination and modelling of high-pressure phase behavior for the binary system $\mathrm{CO}_{2}+$ cyclooctane 


\title{
Highlights
}

- High-pressure phase equilibria were measured for the system $\mathrm{CO}_{2}+$ cyclooctane

- 80 bubble points and 16 dew points were acquired

- The experimental data were obtained using a variable volume high-pressure cell

- The studied binary system probably exhibits a type $\mathrm{V}$ phase behavior

- Data were correlated with the Peng-Robinson equation and advanced mixing rules

\begin{abstract}
Using a synthetic method, the phase behavior of the $\mathrm{CO}_{2}(1)+$ cyclooctane (2) binary system was for the first time experimentally studied between $292.95 \mathrm{~K}$ and $373.55 \mathrm{~K}$. In this temperature range, the bubble- and dew-point pressures, ranging from 13.2 to 183.4 bar were measured for carbon dioxide mole fractions between 0.1014 and 0.9701 . A total of 96 experimental data points were acquired. The experimental data were obtained using a highpressure cell by visual observation of phase transitions. These measurements made it possible to conclude that the studied binary system probably exhibits a type $\mathrm{V}$ phase behavior in the classification scheme of Van Konynenburg and Scott. In particular, the experimental temperature of the suspected lower critical end point (LCEP) was found to be $303 \mathrm{~K}$. Despite the complexity of the phase behavior, the experimental data could be accurately correlated with the Peng-Robinson equation of state combined with sophisticated mixing rules that either involve temperature-dependent binary interaction parameters $\left(k_{i j}(T)\right)$ or that embed the residual part of the Wilson activity coefficient model.
\end{abstract}

\section{Keywords}

Phase equilibria, High pressure cell, Peng-Robinson equation of state, Advanced mixing rules, Type V binary system.

Experimental determination and modelling of high-pressure phase behavior for the binary system $\mathrm{CO}_{2}+$ cyclooctane 


\section{Introduction}

The continuous increase of research articles devoted to high-pressure phase equilibria during the last 35 years shows the vitality of the supercritical fluid domain and the development of high-pressure processes [1,2]. Among these numerous papers, $\mathrm{CO}_{2}$ remains the pure compound that is involved the most often in the investigated binary, ternary or more complex mixtures [3-7], especially because it is widely used in supercritical fluid separation processes. $\mathrm{CO}_{2}$ is also a major greenhouse gas, and one of the technologies implemented to achieve carbon neutrality is the gas injection technique using captured $\mathrm{CO}_{2}$, which is now routinely employed, not only to enhance oil recovery, but also to geologically store the $\mathrm{CO}_{2}$. Phase equilibrium data of mixtures containing carbon dioxide are therefore still needed to design and improve industrial operations as well as to estimate the parameters of thermodynamic models [8-10].

Binary mixtures containing $\mathrm{CO}_{2}$ and a hydrocarbon have been extensively measured and a vast amount of data involving a basic naphthene or aromatic component such as benzene, toluene, xylene, cyclopentane or cyclohexane are available [11,12]. However, a lack of data is observed for systems containing less common compounds. As an example, although experimental phase equilibrium data for the $\mathrm{CO}_{2}+$ cyclopentane and $\mathrm{CO}_{2}+$ cyclohexane binary systems are rather abundant, to the best of our knowledge, no experimental data were published for the binary system $\mathrm{CO}_{2}+$ cycloheptane. For the $\mathrm{CO}_{2}+$ cyclooctane system, only 3 solubility data at atmospheric pressure have been reported [13]. Broadly speaking, phase equilibrium data of mixtures involving a naphthenic compound that contains more than 6 carbon atoms in its ring are extremely scarce $[11,14]$.

The objective of this study is to obtain new experimental vapor-liquid equilibrium (VLE) data for the system $\mathrm{CO}_{2}(1)+$ cyclooctane (2) at high pressure. The experiments were conducted in a high-pressure cell with a sapphire window enabling direct observation of the phase transition. The experimental results were correlated with the Peng-Robinson (PR) equation of state $($ EoS) $[15,16]$ armed with advanced mixing rules (MR) [17-19].

Experimental determination and modelling of high-pressure phase behavior for the binary system $\mathrm{CO}_{2}+$ cyclooctane 


\section{Experimental section}

\subsection{Materials}

The carbon dioxide used in this study was supplied by Messer France and had a mass fraction purity higher than 0.999. Cyclooctane was supplied by Aldrich with a molar fraction purity higher than 0.990 and was used without any further purification.

\subsection{Apparatus and procedure}

Bubble and dew pressures were measured using a variable volume high-pressure cell. More details concerning the equipment used and the method can be found in our previous papers [20-22]. Briefly, the technique used to carry out vapor-liquid equilibrium measurements was based on a synthetic method (Synthetic-visual method with Variablevolume cell, "SynVisVar" according to Dohrn et al. [1,2]) which avoids sampling and analyses of both phases.

The experimental apparatus consisted of a stainless steel high-pressure cell with variable volume marketed by Top Industrie S.A.. One end of the cell was closed by a movable piston and the other end by a sapphire window allowing a visual observation of the equilibrium cell. A second sapphire window was fixed on the cylinder wall in order to illuminate the fluid with an optical fiber. Visualization was possible through the use of an endoscope placed right in front of the window.

The mixture was permanently homogenized thanks to a small magnetic bar and an external magnetic stirrer. The cell volume could be varied between 8 and $30 \mathrm{~cm}^{3}$ and the internal temperature was kept constant by circulating a thermo-regulated heat-carrier fluid through three lines in the cell.

The temperature was precisely measured with a thermometer (AOIP brand, accuracy of $0.1 \mathrm{~K}$ ) connected to a calibrated platinum resistance inserted into the cell, while pressure was measured by a piezoresistive-silicon pressure transducer (Kulite) directly placed inside the cell to minimize dead volumes. For each investigated temperature ranging from $293.15 \mathrm{~K}$ to $373.15 \mathrm{~K}$, calibration of the pressure transducer was carried out between 0.1 and $100 \mathrm{MPa}$ by means of a dead-weight gauge (Budenberg) with an accuracy of $0.02 \%$.

The equilibrium cell was first loaded with a known amount of cyclooctane by vacuum extraction. The exact mass of liquid introduced in the cell was determined using a precision balance (Ohaus) with an accuracy of $0.0001 \mathrm{~g}$. $\mathrm{CO}_{2}$ was then added under pressure. For this purpose, the gas was initially loaded onto a light weight tank fixed on the plate of a high mass / high precision balance (Sartorius). The maximum weighing capacity of this balance was

Experimental determination and modelling of high-pressure phase behavior for the binary system $\mathrm{CO}_{2}+$ cyclooctane 
$2000 \mathrm{~g}$ whereas its accuracy was $0.001 \mathrm{~g}$. The $\mathrm{CO}_{2}$ reservoir tank was connected to the cell by a flexible high-pressure capillary. The exact mass of $\mathrm{CO}_{2}$ injected in the cell was thus determined by weighing the reservoir tank during the filling. Once done, the molar composition of the binary mixture contained in the cell (i.e. $\mathrm{CO}_{2}+$ cyclooctane) could be straightforwardly calculated. From this procedure, the standard uncertainties in mass introduced were estimated to be lower than $0.01 \mathrm{~g}$ for liquid cyclooctane and $0.005 \mathrm{~g}$ for $\mathrm{CO}_{2}$. When the desired temperature cell was reached, the pressure was slowly increased until the system became homogeneous. Due to supersaturation effects, the phase boundaries were evaluated by determining the disappearance conditions of one phase instead of its appearance meaning that measurements were carried out by observing the disappearance of the vapor phase (for a bubble point-pressure measurement) or the liquid phase (for a dew-point pressure measurement) at constant temperature. The method consisted first in observing the formation of a new phase by gradually changing the pressure and then reversing the direction of this variation in a stepwise fashion so as to detect the disappearance of the last phase formed. The procedure was repeated five times by reducing the increment. By doing so, reproducibility of the measured pressure at which the phase disappeared was 0.2 bar for bubble point pressure and 0.4 for dew point pressure while temperature was measured with an accuracy of $0.1 \mathrm{~K}$.

Experimental determination and modelling of high-pressure phase behavior for the binary system $\mathrm{CO}_{2}+$ cyclooctane 


\section{Experimental results}

For 11 different global compositions ranging from 0.1014 to $0.9701 \mathrm{CO}_{2}$ mole fraction, a total of 80 bubble-point pressures and temperatures and 16 upper dew point pressures and temperatures were experimentally measured for the $\mathrm{CO}_{2}+$ cyclooctane binary system. Lower dew-point pressures were expected to be extremely small for the studied binary system so that it was not tried to measure them. The results are recorded in Table 1 for the 11 isopleths.

Table 1. Experimental bubble-point and dew-point pressures and temperatures for the $\mathrm{CO}_{2}+$ cyclooctane binary mixture at 11 different $\mathrm{CO}_{2}$ mole fractions as well as the uncertainties ${ }^{\text {a,b }}$.

\begin{tabular}{|c|c|c|c|c|c|c|c|c|c|c|c|}
\hline \multicolumn{2}{|c|}{$x_{\mathrm{CO} 2}=0.1014 \pm 0.0011$} & \multicolumn{2}{|c|}{$x_{\mathrm{CO} 2}=0.1990 \pm 0.0010$} & \multicolumn{2}{|c|}{$x_{\mathrm{CO} 2}=0.2996 \pm 0.0008$} & \multicolumn{2}{|c|}{$x_{\mathrm{CO} 2}=0.4055 \pm 0.0008$} & \multicolumn{2}{|c|}{$x_{\mathrm{CO} 2}=0.5007 \pm 0.0007$} & \multicolumn{2}{|c|}{$x_{\mathrm{CO} 2}=0.6000 \pm 0.0005$} \\
\hline$T / \mathrm{K}$ & $P /$ bar & $T / \mathrm{K}$ & $P /$ bar & $T / \mathrm{K}$ & $P /$ bar & $T / \mathrm{K}$ & $P /$ bar & $T / \mathrm{K}$ & $P /$ bar & $T / \mathrm{K}$ & $P /$ bar \\
\hline 293.05 & 13.2 & 293.15 & 24.5 & 293.15 & 34.7 & 292.95 & 42.6 & 293.25 & 47.6 & 293.05 & 50.0 \\
\hline 302.45 & 15.5 & 302.45 & 28.5 & 302.65 & 40.7 & 302.45 & 50.9 & 302.65 & 57.5 & 302.75 & 61.8 \\
\hline 312.65 & 18.2 & 313.15 & 33.0 & 312.45 & 47.1 & 312.35 & 59.3 & 312.75 & 68.5 & 312.65 & 74.7 \\
\hline 323.15 & 20.8 & 323.25 & 37.4 & 322.55 & 53.3 & 322.35 & 68.2 & 322.65 & 79.8 & 322.85 & 88.9 \\
\hline 332.55 & 23.1 & 332.65 & 41.4 & 332.75 & 59.7 & 332.55 & 77.0 & 333.05 & 91.4 & 333.05 & 103.4 \\
\hline 342.65 & 25.3 & 342.65 & 45.3 & 342.35 & 65.5 & 343.15 & 86.1 & 343.15 & 102.5 & 343.05 & 117.4 \\
\hline 352.75 & 27.4 & 352.85 & 49.3 & 352.55 & 71.3 & 352.55 & 93.9 & 353.05 & 112.7 & 352.95 & 130.4 \\
\hline 362.95 & 29.5 & 362.65 & 53.0 & 362.65 & 76.8 & 362.65 & 101.3 & 362.85 & 122.6 & 362.75 & 142.5 \\
\hline 373.45 & 31.5 & 372.35 & 56.2 & 372.65 & 81.9 & 373.15 & 108.9 & 373.15 & 131.8 & 373.25 & 154.1 \\
\hline \multicolumn{2}{|c|}{$x_{\mathrm{CO} 2}=0.7515 \pm 0.0007$} & \multicolumn{2}{|c|}{$x_{\mathrm{CO} 2}=0.8445 \pm 0.0005$} & \multicolumn{2}{|c|}{$x_{\mathrm{CO} 2}=0.9393 \pm 0.0004$} & \multicolumn{2}{|c|}{$x_{\mathrm{CO} 2}=0.9602 \pm 0.0002$} & \multicolumn{2}{|c|}{$x_{\mathrm{CO} 2}=0.9701 \pm 0.0002$} & & \\
\hline$T / \mathrm{K}$ & $P /$ bar & $T / \mathrm{K}$ & $P /$ bar & $T / \mathrm{K}$ & P/bar & $T / \mathrm{K}$ & P/bar & $T / \mathrm{K}$ & $P /$ bar & & \\
\hline 293.05 & 51.2 & 293.25 & 51.7 & 292.95 & 52.5 & 293.05 & 54.7 & 293.25 & 55.4 & & \\
\hline 303.05 & 64.5 & 302.85 & 64.7 & 303.05 & 66.5 & 303.15 & 69.5 & 303.35 & 70.6 & & \\
\hline 312.95 & 79.7 & 312.65 & 79.8 & 312.65 & 81.7 & 313.25 & 84.8 & 312.95 & 84.1 & & \\
\hline 322.95 & 96.8 & 322.95 & 98.1 & 323.05 & 99.0 & 322.95 & 98.3 & 322.95 & 95.3 & & \\
\hline 333.15 & 115.9 & 333.05 & 119.2 & 332.85 & 117.7 & 333.05 & 112.4 & 333.15 & 104.7 & & \\
\hline 343.45 & 134.8 & 342.85 & 138.6 & 342.65 & 134.6 & 343.05 & 122.9 & 342.85 & 108.5 & & \\
\hline 353.35 & 151.0 & 353.05 & 156.2 & 353.75 & 150.4 & 353.15 & 129.7 & 353.05 & 109.7 & & \\
\hline 363.35 & 165.7 & 363.05 & 171.1 & 363.25 & 161.2 & 362.95 & 133.1 & & & & \\
\hline 373.55 & 179.3 & 372.95 & 183.4 & 373.15 & 169.9 & & & & & & \\
\hline
\end{tabular}

${ }^{\mathrm{a}}$ Bold data are dew points; the rest are bubble points.

${ }^{\mathrm{b}}$ Standard uncertainties $\mathrm{u}$ are $\mathrm{u}(T)=0.1 \mathrm{~K}$ and $\mathrm{u}(P)=0.2$ bar for bubble points and $\mathrm{u}(\mathrm{P})=0.4$ bar for dew points.

Using a Microsoft Excel type solver, bubble and dew curves for constant composition can be approximated by polynomials from which isothermal P-x-y sections can be calculated at any temperature in the investigated temperature range. For nine temperatures ranging from $293.15 \mathrm{~K}$ to $373.15 \mathrm{~K}$ with a step of $10 \mathrm{~K}$, isothermal $(P, x, y)$ data obtained from the original measurements are given in Table 2 and are shown in Fig. 1. 
Table 2. Isothermal $(P, x, y)$ data for the $\mathrm{CO}_{2}+$ cyclooctane binary system at nine different temperatures calculated from the original measurements reported in Table 1.

\begin{tabular}{|c|c|c|c|c|c|c|c|c|c|c|c|c|c|c|}
\hline \multicolumn{3}{|c|}{$T / K=293.15$} & \multicolumn{3}{|c|}{$T / K=303.15$} & \multicolumn{3}{|c|}{$T / K=313.15$} & \multicolumn{3}{|c|}{$T / K=323.15$} & \multicolumn{3}{|c|}{$T / K=333.15$} \\
\hline $\mathrm{P} / \mathrm{bar}$ & $\mathrm{x}_{\mathrm{CO}_{2}}$ & $\mathrm{y}_{\mathrm{CO}_{2}}$ & P/bar & $\mathrm{x}_{\mathrm{CO}_{2}}$ & $\mathrm{y}_{\mathrm{CO}_{2}}$ & P/bar & $\mathrm{x}_{\mathrm{CO}_{2}}$ & $\mathrm{y}_{\mathrm{CO}_{2}}$ & P/bar & $\mathrm{x}_{\mathrm{CO}_{2}}$ & $\mathrm{y}_{\mathrm{CO}_{2}}$ & P/bar & $\mathrm{x}_{\mathrm{CO}_{2}}$ & $\mathrm{y}_{\mathrm{CO}_{2}}$ \\
\hline 13.1 & 0.1014 & - & 15.8 & 0.1014 & - & 18.3 & 0.1014 & - & 20.8 & 0.1014 & - & 23.2 & 0.1014 & - \\
\hline 24.5 & 0.1990 & - & 28.8 & 0.1990 & - & 33.1 & 0.1990 & - & 37.3 & 0.1990 & - & 41.5 & 0.1990 & - \\
\hline 34.7 & 0.2996 & - & 41.1 & 0.2996 & - & 47.4 & 0.2996 & - & 53.8 & 0.2996 & - & 59.9 & 0.2996 & - \\
\hline 42.8 & 0.4055 & - & 51.4 & 0.4055 & - & 60.1 & 0.4055 & - & 68.9 & 0.4055 & - & 77.6 & 0.4055 & - \\
\hline 47.5 & 0.5007 & - & 58.0 & 0.5007 & - & 69.1 & 0.5007 & - & 80.3 & 0.5007 & - & 91.5 & 0.5007 & - \\
\hline 50.1 & 0.6000 & - & 62.3 & 0.6000 & - & 75.5 & 0.6000 & - & 89.4 & 0.6000 & - & 103.5 & 0.6000 & - \\
\hline 51.3 & 0.7515 & - & 64.5 & 0.7515 & - & 80.2 & 0.7515 & - & 97.5 & 0.7515 & - & 115.7 & 0.7515 & - \\
\hline 51.8 & 0.8445 & - & 64.5 & 0.8445 & - & 80.8 & 0.8445 & - & 99.4 & 0.8445 & - & 119.0 & 0.8445 & - \\
\hline 52.8 & 0.9393 & - & 66.4 & 0.9393 & - & 82.5 & 0.9393 & - & 100.0 & - & 0.9393 & 117.8 & - & 0.9393 \\
\hline 54.9 & 0.9602 & - & 69.4 & 0.9602 & - & 84.5 & 0.9602 & - & 99.1 & - & 0.9602 & 112.2 & - & 0.9602 \\
\hline 55.2 & 0.9701 & - & 70.5 & 0.9701 & - & 84.1 & - & 0.9701 & 95.9 & - & 0.9701 & 104.4 & - & 0.9701 \\
\hline \multicolumn{3}{|c|}{$T / K=343.15$} & \multicolumn{3}{|c|}{$T / K=353.15$} & \multicolumn{3}{|c|}{$T / K=363.15$} & \multicolumn{3}{|c|}{$T / K=373.15$} & & & \\
\hline $\mathrm{P} / \mathrm{bar}$ & $\mathrm{x}_{\mathrm{CO}_{2}}$ & $\mathrm{y}_{\mathrm{CO}_{2}}$ & P/bar & $\mathrm{x}_{\mathrm{CO}_{2}}$ & $\mathrm{y}_{\mathrm{CO}_{2}}$ & P/bar & $\mathrm{x}_{\mathrm{CO}_{2}}$ & $\mathrm{y}_{\mathrm{CO}_{2}}$ & P/bar & $\mathrm{x}_{\mathrm{CO}_{2}}$ & $\mathrm{y}_{\mathrm{CO}_{2}}$ & & & \\
\hline 25.4 & 0.1014 & - & 27.5 & 0.1014 & - & 29.5 & 0.1014 & - & 31.4 & 0.1014 & - & & & \\
\hline 45.6 & 0.1990 & - & 49.5 & 0.1990 & - & 53.1 & 0.1990 & - & 56.5 & 0.1990 & - & & & \\
\hline 65.9 & 0.2996 & - & 71.7 & 0.2996 & - & 77.1 & 0.2996 & - & 82.1 & 0.2996 & - & & & \\
\hline 86.1 & 0.4055 & - & 94.2 & 0.4055 & - & 101.8 & 0.4055 & - & 108.8 & 0.4055 & - & & & \\
\hline 102.4 & 0.5007 & - & 112.9 & 0.5007 & - & 122.8 & 0.5007 & - & 131.8 & 0.5007 & - & & & \\
\hline 117.4 & 0.6000 & - & 130.7 & 0.6000 & - & 143.0 & 0.6000 & - & 153.9 & 0.6000 & - & & & \\
\hline 133.7 & 0.7515 & - & 150.8 & 0.7515 & - & 166.0 & 0.7515 & - & 178.6 & 0.7515 & - & & & \\
\hline 138.4 & 0.8445 & - & 156.4 & 0.8445 & - & 171.8 & 0.8445 & - & 183.3 & 0.8445 & - & & & \\
\hline 134.8 & - & 0.9393 & 149.8 & - & 0.9393 & 161.7 & - & 0.9393 & 169.5 & & 0.9393 & & & \\
\hline 122.8 & - & 0.9602 & 130.0 & - & 0.9602 & 133.0 & - & 0.9602 & & & & & & \\
\hline 108.7 & - & 0.9701 & 109.6 & - & 0.9701 & & & & & & & & & \\
\hline
\end{tabular}

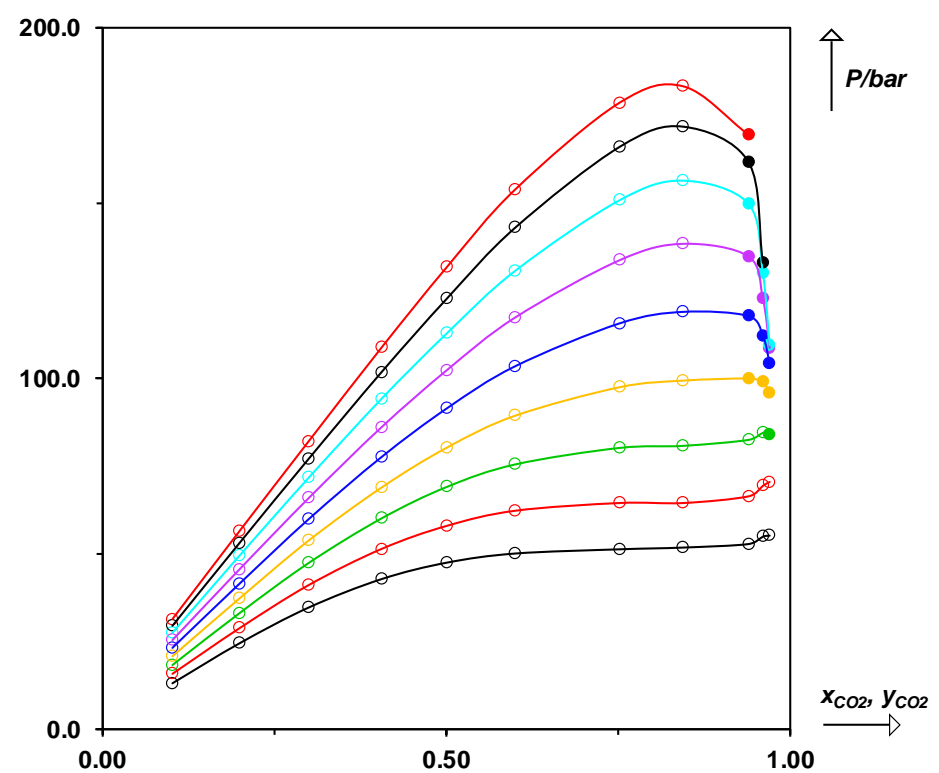

Figure 1. Isothermal $(P, x, y)$ cross-sections for the system $\mathrm{CO}_{2}+$ cyclooctane at temperatures ranging from $293.15 \mathrm{~K}$ to $373.15 \mathrm{~K}$ with a step of $10 \mathrm{~K}$. ०: experimental bubble point. •: experimental dew point. The continuous line simply connects the experimental data points through spline functions. 


\section{Modeling and discussion}

Before correlating the measured data with the Peng-Robinson EoS armed with sophisticated mixing rules, it is important to notice that at $\mathrm{T}_{2}=303.15 \mathrm{~K}$, the experimentally measured bubble curve exhibits a horizontal plateau: for compositions 0.7515 and 0.8445 , the measured bubble pressures are exactly the same $\left(\mathrm{P}_{\text {bubble }}=64.5\right.$ bar $)$. The presence of this horizontal plateau strongly suggests - at these specific temperature and pressure $(\mathrm{T} / \mathrm{K}=303.15$ and $\mathrm{P} / \mathrm{bar}=64.5)-$ the existence of a lower critical end point $\left(\mathrm{LCEP}_{\mathrm{LL}}\right)$, i.e., of an equilibrium between a vapor phase and a liquid-liquid critical point [23] (the liquid-liquid critical composition is somewhere between 0.7515 and 0.8445 ). Let us indeed recall that a $\mathrm{CEP}_{\mathrm{LL}}$ is characterized by the simultaneous presence of an inflection point and a horizontal tangent on the bubble curve (refer to Fig. 20 (panel e) in [23] for more details) so that the bubble curve necessarily exhibits a horizontal plateau in the immediate vicinity of the CEP composition. In other words, a 3-phase line is presumably born at $\mathrm{T}_{2}=303.15 \mathrm{~K}$. The temperature range in which such a 3-phase line exists seems to be very narrow since for temperatures ranging from 323 to $373 \mathrm{~K}$, classical phase behaviors (as those observed in type I systems of the classification scheme of Van Konynenburg and Scott $[23,24]$ ) are observed. At $313.15 \mathrm{~K}$, the existence of very close bubble-point pressures at $\mathrm{x}_{\mathrm{co} 2}=0.75$ and 0.84 is compatible with the presence of a liquid-liquid region above a 3-phase line. In such a case, the 2 measured points for $\mathrm{x}_{\mathrm{co} 2}=0.75$ and 0.84 would not be truly bubble points like the others since they would correspond to the disappearance of a liquid phase. It is however worth recalling that adjectives "liquid" and "gas" lose their common sense in the critical region. The simultaneous presence of a liquid-vapor critical point (at around 84.6 bar for a mole fraction of about 0.965 ) leads one to believe that the $\mathrm{CO}_{2}+$ cyclooctane binary system exhibits a type V (or IV) behavior in the classification proposed by Van Konynenburg and Scott. However, it is important to emphasize that no liquid-liquid-vapor equilibrium was observed during our experiments so that we cannot exclude that the $\mathrm{CO}_{2}+$ cyclooctane is a type I binary system. This lack of formal conclusion is due to the very narrow domain of existence of the probable three-phase line and to the lack of experimental data in this region. Undoubtedly, more experiments would be required in order to confirm the occurrence of LLVE and the type of phase behavior.

It was thus a challenge to check if cubic EoS armed with sophisticated mixing rules could reproduce such a type V phase behavior. In this study, it was decided to select the PR EoS in order to represent the thermodynamics of the $\mathrm{CO}_{2}+$ cyclooctane system:

Experimental determination and modelling of high-pressure phase behavior for the binary system $\mathrm{CO}_{2}+$ cyclooctane 


$$
P(T, v, z)=\frac{R \cdot T}{v-b_{m}}-\frac{a_{m}}{v\left(v+b_{m}\right)+b_{m}\left(v-b_{m}\right)}
$$

Two sets of mixing rules were used:

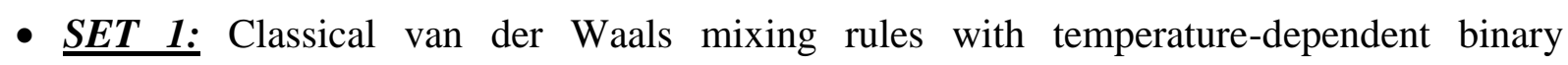
interaction parameters $\left(k_{i j}(T)\right)$ :

With:

$$
\begin{aligned}
& b_{m}=\sum_{i=1}^{N C} z_{i} b_{i} \\
& a_{m}=\sum_{i=1}^{N C} \sum_{j=1}^{N C} z_{i} z_{j} \sqrt{a_{i} a_{j}}\left(1-k_{i j}(T)\right)
\end{aligned}
$$

Such mixing rules are those used in the well-established PPR78 model [25,26]. In the latter model, a group-contribution method was especially developed to calculate the 2 parameters $A_{i j}$ and $B_{i j}$. In this study, they were fitted to experimental data in order to minimize the mean absolute deviations, at specified temperature and pressure, between calculated and experimental liquid phase and gas phase compositions. This is indeed the objective function which was systematically used during the development of the PPR78 model. The optimal values were found to be: $A_{12}=144.3 \mathrm{MPa}$ and $B_{12}=407.6 \mathrm{MPa}$. 
- $\underline{\text { SET 2: }}$ Advanced mixing rules that combine the residual part of the Wilson [27] activity coefficient model $\left(a_{\text {residual }}^{E, \text { Wilson }}=a^{E, \text { Wilson }}-a_{\text {combinatorial }}^{\text {E,Wilson }}\right)$ and the PR EoS:

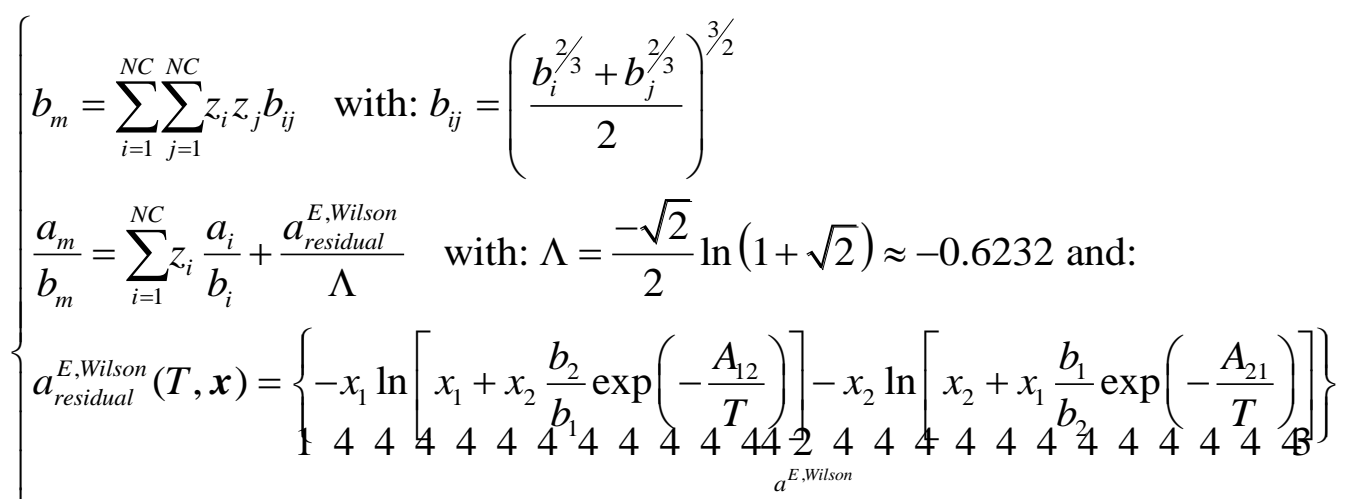

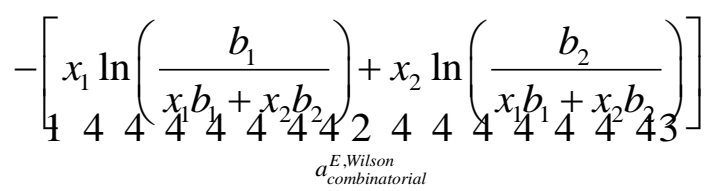

Such mixing rules (MR) can be seen as a mix between Huron-Vidal [28] MR and those used in the UMR-PRU [29-33] model. Here also, the two parameters $A_{12}$ and $A_{21}$ were fitted to experimental data. The optimal values that minimize the deviations between calculated and experimental phase compositions are: $A_{12}=309.4 \mathrm{~K}$ and $A_{21}=4.566 \mathrm{~K}$.

In all cases, pure-component parameters $\left(a_{i}\right.$ and $\left.b_{i}\right)$ were classically calculated by:

$$
\left\{\begin{array}{l}
a_{i}(T)=a_{c, i} \cdot \alpha_{i}(T) \\
\alpha_{i}(T)=\left[1+m_{i}\left(1-\sqrt{T / T_{c, i}}\right)\right]^{2} \\
m_{i}=0.37464+1.54226 \omega_{i}-0.26992 \omega_{i}^{2} \\
a_{c, i}=\Omega_{a} \cdot \frac{R^{2} T_{c, i}^{2}}{P_{c, i}} \\
b_{i}=\Omega_{b} \cdot \frac{R T_{c, i}}{P_{c, i}} \\
\mathrm{X}=[1+\sqrt[3]{4-2 \sqrt{2}}+\sqrt[3]{4+2 \sqrt{2}}]^{-1} \approx 0.25308 \\
\Omega_{a}=\frac{8+40 X}{49-37 X} \approx 0.45724 \\
\Omega_{b}=\frac{X}{X+3} \approx 0.07780
\end{array}\right.
$$

Pure-component properties (experimental critical temperature, $T_{c, i}$, pressure, $P_{c, i}$, and acentric factor, $\omega_{i}$ ) considered in this work stem from the DIPPR database. In this study, the Soave [34] $\alpha$-function was selected because, as shown in [35-37], it holds the Experimental determination and modelling of high-pressure phase behavior for the binary system $\mathrm{CO}_{2}+$ cyclooctane 
thermodynamically consistent positive - monotonically decreasing - convex behavior, within the temperature domain that characterizes the phase-equilibrium data acquired in this study.

\subsection{Discussion on the correlation of the measured data with the PR EOS armed with classical van der Waals mixing rules and temperature-dependent binary interaction parameters}

Fig. 2 highlights that the classical VdW mixing rules with temperature-dependent binary interaction parameters predict a type III phase diagram meaning that non-experimentallyobserved three-phase lines are predicted at low temperatures (293 and $303 \mathrm{~K}$ ) as shown in Fig. 3. With this first set of mixing rules (see Fig. 3), dew-point pressures are predicted with high accuracy. Apart from the critical region, bubble-point pressures tend to be underestimated by the model. The critical region is particularly difficult to reproduce here because the temperatures at which the measurements were performed are slightly above that of the calculated UCEP $\left(\mathrm{T}_{\mathrm{UCEP}}=316 \mathrm{~K}\right.$ ). In this region (see in particular the calculated isothermal phase diagrams at 323 and $333 \mathrm{~K}$ ), the disappearance of the three-phase line distorts the isothermal phase diagrams by inducing the presence of inflection points on the bubble curve which makes extremely difficult a faithful reproduction of the data. Even if this first set of mixing rules does not predict - as experimentally suspected - a type V (or IV) phase diagram, it would be unfair to conclude that such mixing rules are not able to correlate complex systems. Indeed, it is known by experience that a very small number of binary systems exhibit a type V (or IV) phase diagram. As an example, in the homologous series of mixtures containing $\mathrm{CO}_{2}$ and a $n$-alkane, a type IV is only observed for the system $\mathrm{CO}_{2}+n$ $\mathrm{C}_{13}$ whereas mixtures of $\mathrm{CO}_{2}$ with $n-\mathrm{C}_{14}$ or with longer $n$-alkanes exhibit type III phase behavior. Type V (or IV) phase diagrams are thus ephemeral and by slightly modifying the parameters of the EoS, we move from a type IV to a type III phase behavior. In other words, it is really scarce to predict a type IV phase behavior with an EoS.

Experimental determination and modelling of high-pressure phase behavior for the binary system $\mathrm{CO}_{2}+$ cyclooctane 


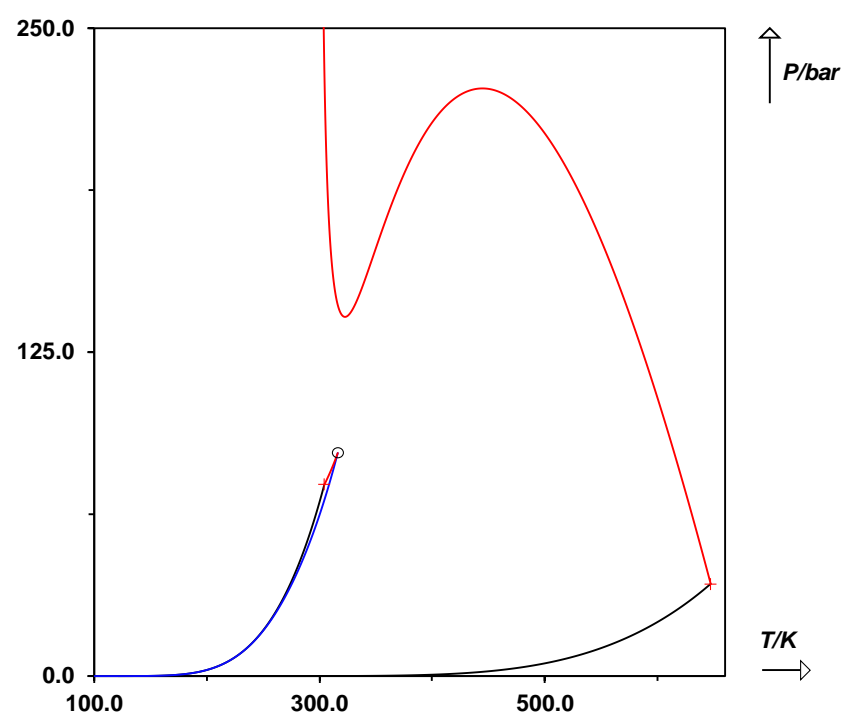

Figure 2. Type III Global Phase Equilibrium Diagram (as named by Cismondi and Michelsen $[38,39])$ of the $\mathrm{CO}_{2}+$ cyclooctane binary system as predicted by the PR EoS armed with classical VdW mixing rules and temperature-dependent binary interaction parameters. 

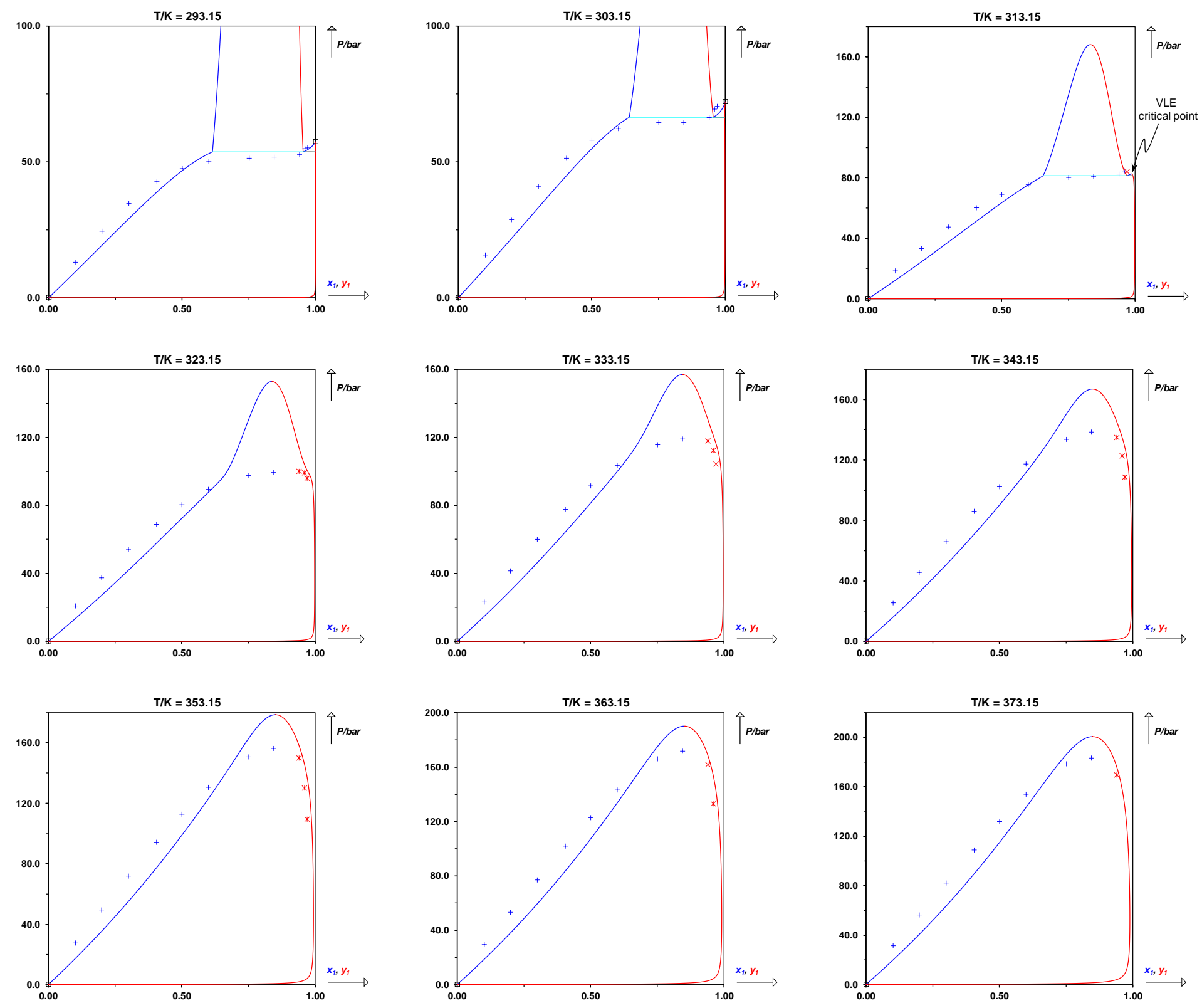

Figure 3. Correlation of the fluid-phase equilibrium data measured in this study (see Table 2) with the PR EoS armed with classical VdW mixing rules and temperature-dependent binary interaction parameters. +: experimental bubble point. $*$ : experimental dew point.

4.2. Discussion on the correlation of the measured data with the PR EOS armed with advanced mixing rules that embed the residual part of the Wilson activity coefficient model

As shown in Figs. 4 and 5, such mixing rules predict a type $\mathrm{V}$ phase behavior and make it possible to reproduce the correct topology of the studied binary system. In particular, the model does not predict a three-phase line at 293.15 and $303.15 \mathrm{~K}$. The calculated temperature of the LCEP $\left(\mathrm{T}_{\mathrm{LCEP}}=306.15 \mathrm{~K}\right)$ is only $3 \mathrm{~K}$ above the alleged experimental value. Moreover, 
at $\mathrm{T}_{3}=313.15 \mathrm{~K}$, it is noticeable that the model predicts with high accuracy the temperature, pressure and composition of the VLE critical point. The unique deficiency of the model is the poor prediction - at temperatures above $313.15 \mathrm{~K}$ - of bubble-point pressures for the 2 compositions $\left(\mathrm{x}_{1}=0.7515\right.$ and $\left.\mathrm{x}_{1}=0.8445\right)$ that felt in the liquid-liquid region at $313.15 \mathrm{~K}$. As previously stated, this is the consequence of the disappearance of the 3-phase line that causes inflection points to appear on the bubble curve.

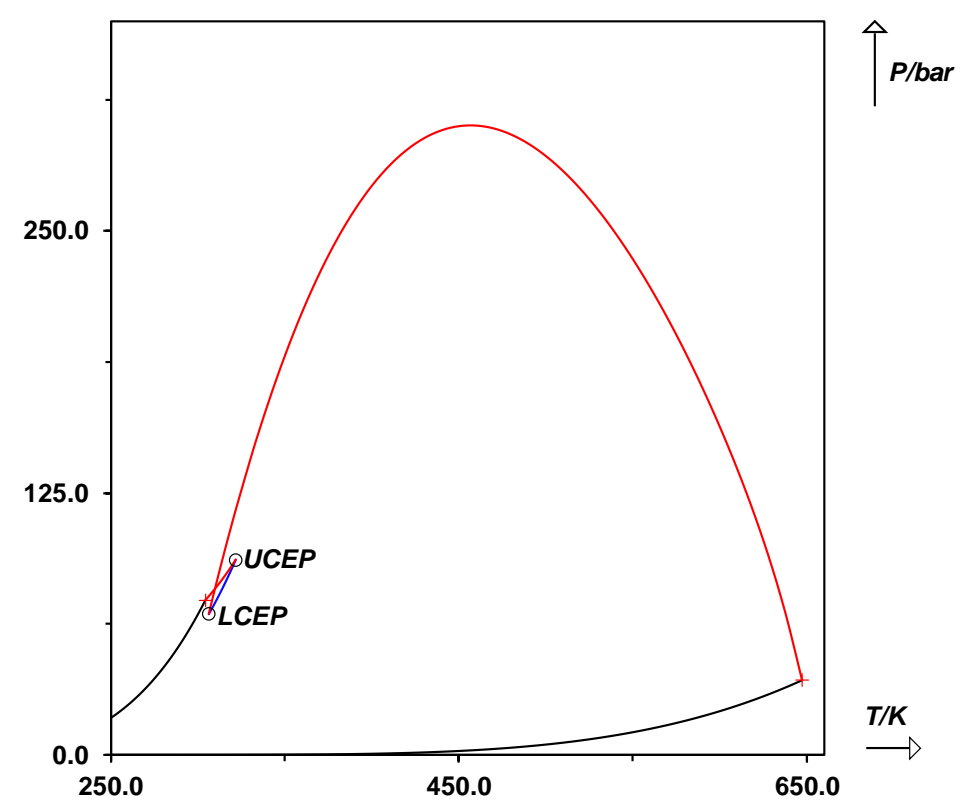

Figure 4. Type V Global Phase Equilibrium Diagram (GPED) of the $\mathrm{CO}_{2}+$ cyclooctane binary system as predicted by the PR EoS armed with advanced mixing rules that embed the residual part of the Wilson activity coefficient model. 

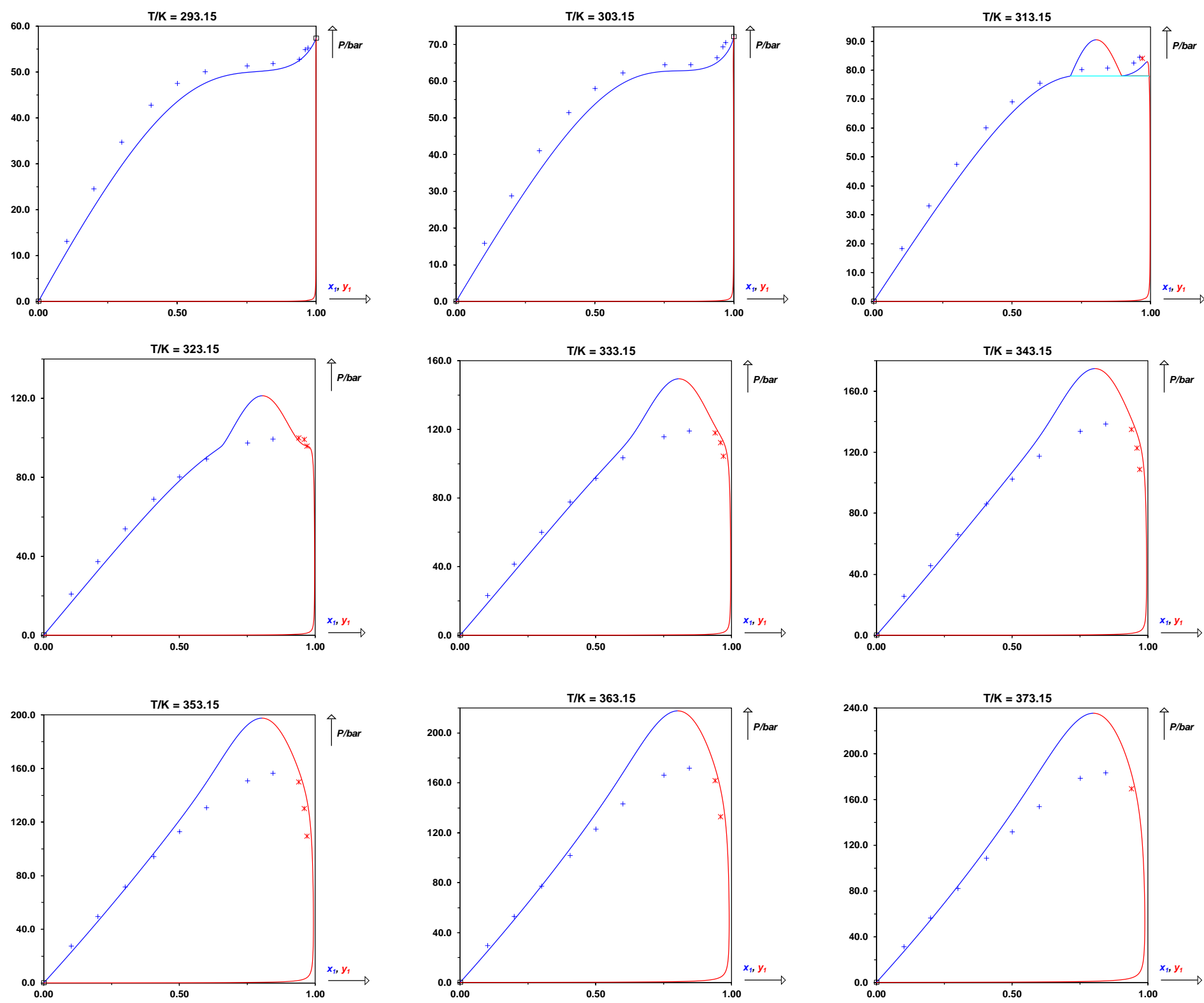

Figure 5. Correlation of the fluid-phase equilibrium data measured in this study (see Table 2) with the PR EoS armed with advanced mixing rules that embed the residual part of the Wilson activity coefficient model. + : experimental bubble point. $*$ : experimental dew point. 


\section{Conclusion}

Using a high-pressure variable volume cell, bubble- and dew-point pressures of the $\mathrm{CO}_{2}+$ cyclooctane binary system were measured for 11 different global compositions in a temperature range varying between 292.95 and $373.55 \mathrm{~K}$. A total of 96 experimental data points, ranging from 13.2 to 183.4 bar, were measured.

The main conclusion of this investigation is that the studied binary system either exhibits a type I or a type V phase behavior in the classification scheme of Van Konynenburg and Scott. It was indeed experimentally observed that at $303.15 \mathrm{~K}$, two mixtures with very different global compositions $(0.7515$ and 0.8445$)$ have exactly the same bubble-point pressure $(\mathrm{P}=$ 64.5 bar). Starting from this observation, 2 possibilities arise:

1. we could argue that considering the experimental uncertainty, these two bubble-point pressures are not exactly identical and that the measured bubble-point pressure at $\mathrm{x}=0.8445$ is in fact slightly higher than that at $\mathrm{x}=0.7515$. In such a case, we have to conclude that the $\mathrm{CO}_{2}+$ cyclooctane system is a type-I system in the classification scheme of Van Konynenburg and Scott.

2. It is assumed that the two bubble-point pressures are identical what makes necessarily appear an inflexion point with a horizontal tangent on the bubble curve which is the characteristic of a critical end point. In other words, a 3-phase line starts or ends at $303.15 \mathrm{~K}$. However, the measured phase diagram at $293.15 \mathrm{~K}$ clearly indicates that there is no 3-phase line at this temperature (the bubble-curve is a monotonically increasing function of composition). We can therefore conclude that a 3-phase line is born at $303.15 \mathrm{~K}$. The critical end point is therefore a lower critical end point so that the $\mathrm{CO}_{2}+$ cyclooctane system exhibits a type $\mathrm{V}$ phase behavior.

Both possibilities are perfectly admissible but more experiments are necessary to confirm the type of phase behavior. It is however believed that a new type $\mathrm{V}$ system was discovered. Indeed at $313.15 \mathrm{~K}$, the two measured bubble-point pressures for $\mathrm{x}=0.7515$ and $\mathrm{x}=0.8445$ are still very close ( 80.2 and 80.8 bar) what is totally compatible with the presence of a fluid-fluid 2-phase region (above the 3-phase line) in this composition range.

Although the complexity of the phase behavior, the experimental data could be satisfactorily correlated with the Peng-Robinson equation of state coupled with sophisticated mixing rules. In particular, the Huron-Vidal-Wilson mixing rule, coupled with a quadratic mixing rule for the covolume were able to predict a type $\mathrm{V}$ phase diagram with a LCEP temperature only $3 \mathrm{~K}$ above the alleged experimental value. It is believed that such mixing rules that only use 2 parameters are among the most versatile ones

Experimental determination and modelling of high-pressure phase behavior for the binary system $\mathrm{CO}_{2}+$ cyclooctane 


\section{References}

[1] J.M.S. Fonseca, R. Dohrn, S. Peper, High-pressure fluid-phase equilibria: Experimental methods and systems investigated (2005-2008), Fluid Phase Equilibria. 300 (2011) 1-69. https://doi.org/10.1016/j.fluid.2010.09.017.

[2] S. Peper, J.M.S. Fonseca, R. Dohrn, High-pressure fluid-phase equilibria: Trends, recent developments, and systems investigated (2009-2012), Fluid Phase Equilibria. 484 (2019) 126-224. https://doi.org/10.1016/j.fluid.2018.10.007.

[3] P. Theveneau, X. Xu, O. Baudouin, J.-N. Jaubert, P. Ceragioli, C. Coquelet, Vapor-liquid equilibria of the $\mathrm{CH}_{4}+\mathrm{CO}_{2}+\mathrm{H}_{2} \mathrm{~S}$ ternary system with two different global compositions: experiments and modeling, J. Chem. Eng. Data. 65 (2020) 1802-1813. https://doi.org/10.1021/acs.jced.9b01082.

[4] C. Latsky, C.E. Schwarz, High pressure vapor-liquid equilibrium data for the quaternary carbon dioxide +1 -decanol + 3,7-dimethyl-1-octanol $+n$-dodecane system, J. Chem. Eng. Data. 64 (2019) 5785-5796. https://doi.org/10.1021/acs.jced.9b00740.

[5] C. Latsky, N.S. Mabena, C.E. Schwarz, High pressure phase behaviour for the $\mathrm{CO}_{2}+$ ndodecane + 3,7-dimethyl-1-octanol system, The Journal of Supercritical Fluids. 149 (2019) 138-150. https://doi.org/10.1016/j.supflu.2019.04.002.

[6] C. Latsky, B. Cordeiro, C.E. Schwarz, High pressure bubble- and dew-point data for systems containing $\mathrm{CO}_{2}$ with 1-decanol and n-hexadecane, Fluid Phase Equilibria. 521 (2020) 112702. https://doi.org/10.1016/j.fluid.2020.112702.

[7] J.-N. Jaubert, P. Borg, L. Coniglio, D. Barth, Phase equilibria measurements and modeling of EPA and DHA ethyl esters in supercritical carbon dioxide, Journal of Supercritical Fluids. 20 (2001) 145-155. https://doi.org/10.1016/S0896-8446(01)00062-6.

[8] Y. Gao, C. Li, S. Xia, P. Ma, Estimation and correlation of phase equilibrium of $\mathrm{CO}_{2}-$ hydrocarbon systems with PRMHV2-UNIFAC and PRMHV2-NRTL models, J. Chem. Eng. Data. 65 (2020) 655-663. https://doi.org/10.1021/acs.jced.9b00890.

[9] J. Wang, X. Yuan, H. Zhao, Y. Wang, X. Zhu, X. Guo, J.-N. Jaubert, Thermophysical properties of switchable-hydrophilicity solvent systems: N,N-Dipropyl-1-propanamine, water and carbon dioxide, The Journal of Chemical Thermodynamics. 143 (2020) 106049. https://doi.org/10.1016/j.jct.2020.106049.

[10] S.ZS. Al Ghafri, J.P.M. Trusler, Phase equilibria of (Methylbenzene + Carbon dioxide + Methane) at elevated pressure: Experiment and modelling, The Journal of Supercritical Fluids. 145 (2019) 1-9. https://doi.org/10.1016/j.supflu.2018.11.012.

[11] S. Vitu, R. Privat, J.-N. Jaubert, F. Mutelet, Predicting the phase equilibria of $\mathrm{CO}_{2}+$ hydrocarbon systems with the PPR78 model (PR EoS and $\mathrm{k}_{\mathrm{ij}}$ calculated through a group contribution method), Journal of Supercritical Fluids. 45 (2008) 1-26. https://doi.org/10.1016/j.supflu.2007.11.015.

[12] S. Sima, J.M. Milanesio, J.I. Ramello, M. Cismondi, C. Secuianu, V. Feroiu, D. Geană, The effect of the naphthenic ring on the VLE of (carbon dioxide + alkane) mixtures, The Journal of Chemical Thermodynamics. 93 (2016) 374-385. https://doi.org/10.1016/j.jct.2015.07.018.

[13] R.J. Wilcock, R. Battino, E. Wilhelm, The solubility of gases in liquids 10 . The solubility of $\mathrm{He}, \mathrm{Ne}, \mathrm{Ar}, \mathrm{Kr}, \mathrm{N} 2, \mathrm{O} 2, \mathrm{CO}, \mathrm{CO} 2, \mathrm{CH} 4, \mathrm{CF} 4$, and SF6 in cyclooctane at 289 to $313 \mathrm{~K}$, The Journal of Chemical Thermodynamics. 9 (1977) 111-115. https://doi.org/10.1016/0021-9614(77)90075-1.

[14] S. Vitu, J.-N. Jaubert, F. Mutelet, Extension of the PPR78 model (Predictive 1978, Peng-Robinson EoS with temperature-dependent $\mathrm{k}_{\mathrm{ij}}$ calculated through a group contribution method) to systems containing naphtenic compounds, Fluid Phase Equilibria. 243 (2006) 9-28. https://doi.org/10.1016/j.fluid.2006.02.004.

Experimental determination and modelling of high-pressure phase behavior for the binary system $\mathrm{CO}_{2}+$ cyclooctane 
[15] D.-Y. Peng, D.B. Robinson, A new two-constant equation of state, Industrial \& $\begin{array}{lllll}\text { Engineering } & \text { Chemistry } & \text { Fundamentals. } & 15 & \text { (1976) }\end{array}$ https://doi.org/10.1021/i160057a011.

[16] A. Pina-Martinez, R. Privat, J.-N. Jaubert, D.-Y. Peng, Updated versions of the generalized Soave $\alpha$-function suitable for the Redlich-Kwong and Peng-Robinson equations of state, Fluid Phase Equilibria. $485 \quad$ (2019) 264-269. https://doi.org/10.1016/j.fluid.2018.12.007.

[17] S. Lasala, P. Chiesa, R. Privat, J.-N. Jaubert, VLE properties of $\mathrm{CO}_{2}$-based binary systems containing $\mathrm{N}_{2}, \mathrm{O}_{2}$ and Ar: experimental measurements and modelling results with advanced cubic equations of state, Fluid Phase Equilibria. 428 (2016) 18-31. https://doi.org/10.1016/j.fluid.2016.05.015.

[18] S. Lasala, P. Chiesa, R. Privat, J.-N. Jaubert, Measurement and prediction of multiproperty data of $\mathrm{CO}_{2}-\mathrm{N}_{2}-\mathrm{O}_{2}-\mathrm{CH}_{4}$ mixtures with the "Peng-Robinson + residual Helmholtz energy-based" model, Fluid Phase Equilibria. 437 (2017) 166-180. https://doi.org/10.1016/j.fluid.2017.01.016.

[19] S. Lasala, P. Chiesa, R. Privat, J.-N. Jaubert, Sizing and operating units for the purification and compression of $\mathrm{CO}_{2}$-based streams: The impact of thermodynamic model accuracy, The Journal of Supercritical Fluids. $140 \quad$ (2018) 336-347. https://doi.org/10.1016/j.supflu.2018.04.010.

[20] S. Vitu, J.-N. Jaubert, J. Pauly, J.-L. Daridon, D. Barth, Phase equilibria measurements of $\mathrm{CO}_{2}+$ methyl cyclopentane and $\mathrm{CO}_{2}+$ isopropyl cyclohexane binary mixtures at elevated pressures, Journal of Supercritical Fluids. 44 (2008) 155-163. https://doi.org/10.1016/j.supflu.2007.10.003.

[21] S. Vitu, J.-N. Jaubert, J. Pauly, J.-L. Daridon, D. Barth, Bubble and dew points of carbon dioxide + a five-component synthetic mixture: experimental data and modeling with the PPR78 model, Journal of Chemical and Engineering Data. 52 (2007) 1851-1855. https://doi.org/10.1021/je7001978.

[22] S. Vitu, J.-N. Jaubert, J. Pauly, J.-L. Daridon, High-pressure phase behaviour of the binary system $\mathrm{CO}_{2}+$ cis-decalin from (292.75 to 373.75$) \mathrm{K}$, Journal of Chemical Thermodynamics. 40 (2008) 1358-1363. https://doi.org/10.1016/j.jct.2008.05.008.

[23] R. Privat, J.-N. Jaubert, Classification of global fluid-phase equilibrium behaviors in binary systems, Chemical Engineering Research and Design. 91 (2013) 1807-1839. https://doi.org/10.1016/j.cherd.2013.06.026.

[24] P.H. Van Konynenburg, R.L. Scott, Critical Lines and Phase Equilibria in Binary Van Der Waals Mixtures, Philosophical Transactions of the Royal Society A: Mathematical, Physical and Engineering Sciences. $298 \quad$ (1980) 495-540. https://doi.org/10.1098/rsta.1980.0266.

[25] J.-N. Jaubert, F. Mutelet, VLE predictions with the Peng-Robinson equation of state and temperature-dependent $\mathrm{k}_{\mathrm{ij}}$ calculated through a group contribution method, Fluid Phase Equilibria. 224 (2004) 285-304. https://doi.org/10.1016/j.fluid.2004.06.059.

[26] J.-W. Qian, J.-N. Jaubert, R. Privat, Phase equilibria in hydrogen-containing binary systems modeled with the Peng-Robinson equation of state and temperature-dependent binary interaction parameters calculated through a group-contribution method, Journal of Supercritical Fluids. 75 (2013) 58-71. https://doi.org/10.1016/j.supflu.2012.12.014.

[27] G.M. Wilson, Vapor-liquid equilibrium. XI. A new expression for the excess free energy of mixing, J. Am. Chem. Soc. 86 (1964) 127-130. https://doi.org/10.1021/ja01056a002.

[28] M.-J. Huron, J. Vidal, New mixing rules in simple equations of state for representing vapour-liquid equilibria of strongly non-ideal mixtures, Fluid Phase Equilibria. 3 (1979) 255-271. https://doi.org/10.1016/0378-3812(79)80001-1. 
[29] E. Voutsas, K. Magoulas, D. Tassios, Universal mixing rule for cubic equations of state applicable to symmetric and asymmetric systems: results with the Peng-Robinson equation of state, Industrial \& Engineering Chemistry Research. 43 (2004) 6238-6246. https://doi.org/10.1021/ie049580p.

[30] E. Voutsas, V. Louli, C. Boukouvalas, K. Magoulas, D. Tassios, Thermodynamic property calculations with the universal mixing rule for EoS $/ G^{\mathrm{E}}$ models: Results with the Peng-Robinson EoS and a UNIFAC model, Fluid Phase Equilibria. 241 (2006) 216-228. https://doi.org/10.1016/j.fluid.2005.12.028.

[31] V. Louli, G. Pappa, C. Boukouvalas, S. Skouras, E. Solbraa, K.O. Christensen, E. Voutsas, Measurement and prediction of dew point curves of natural gas mixtures, Fluid Phase Equilibria. 334 (2012) 1-9. https://doi.org/10.1016/j.fluid.2012.07.028.

[32] G.D. Pappa, C. Perakis, I.N. Tsimpanogiannis, E.C. Voutsas, Thermodynamic modeling of the vapor-liquid equilibrium of the $\mathrm{CO} 2 / \mathrm{H} 2 \mathrm{O}$ mixture, Fluid Phase Equilibria. 284 (2009) 56-63. https://doi.org/10.1016/j.fluid.2009.06.011.

[33] E.G. Petropoulou, E.C. Voutsas, Thermodynamic modeling and simulation of natural gas dehydration using triethylene glycol with the UMR-PRU model, Ind. Eng. Chem. Res. 57 (2018) 8584-8604. https://doi.org/10.1021/acs.iecr.8b01627.

[34] G. Soave, Equilibrium constants from a modified Redlich-Kwong equation of state, Chemical Engineering Science. 27 (1972) 1197-1203. https://doi.org/10.1016/00092509(72)80096-4.

[35] Y. Le Guennec, S. Lasala, R. Privat, J.-N. Jaubert, A consistency test for $\alpha$-functions of cubic equations of state, Fluid Phase Equilibria. 427 (2016) 513-538. https://doi.org/10.1016/j.fluid.2016.07.026.

[36] Y. Le Guennec, R. Privat, S. Lasala, J.-N. Jaubert, On the imperative need to use a consistent $\alpha$-function for the prediction of pure-compound supercritical properties with a cubic equation of state, Fluid Phase Equilibria. 445 (2017) 45-53. https://doi.org/10.1016/j.fluid.2017.04.015.

[37] Y. Le Guennec, R. Privat, J.-N. Jaubert, Development of the translated-consistent $t c-$ $\mathrm{PR}$ and $t c$-RK cubic equations of state for a safe and accurate prediction of volumetric, energetic and saturation properties of pure compounds in the sub- and super-critical domains, Fluid Phase Equilibria. 429 (2016) 301-312. https://doi.org/10.1016/j.fluid.2016.09.003.

[38] M. Cismondi, M.L. Michelsen, Global phase equilibrium calculations: Critical lines, critical end points and liquid-liquid-vapour equilibrium in binary mixtures, The Journal of Supercritical Fluids. 39 (2007) 287-295. https://doi.org/10.1016/j.supflu.2006.03.011.

[39] M. Cismondi, M. Michelsen, Automated calculation of complete Pxy and Txy diagrams for binary systems, Fluid Phase Equilibria. 259 (2007) 228-234. https://doi.org/10.1016/j.fluid.2007.07.019. 